\title{
Retaining health carers: The role of personal and organisation job resources
}

\begin{tabular}{|r|l|}
\hline Journal: & Journal of Organizational Effectiveness: People and Performance \\
\hline Manuscript ID & JOEPP-06-2018-0036.R2 \\
\hline Manuscript Type: & Research Paper \\
\hline Keywords: & $\begin{array}{l}\text { Employee Engagement, Wellbeing, Job Satisfaction, Healthcare } \\
\text { Professionals }\end{array}$ \\
\hline \multicolumn{2}{|l}{} \\
\hline
\end{tabular}

\section{SCHOLARONE \\ Manuscripts}




\section{Retaining health carers: The role of personal and organisation job resources}

\section{Abstract \\ Purpose}

The purpose of this study is to identify key personal and organisational resources that influence the engagement, wellbeing and job satisfaction of healthcare professionals working in Australia.

\section{Design/methodology/approach}

Using the Job Demands-Resources model, this study investigates how employee resources and organisation resources influence engagement, wellbeing and job satisfaction of health professionals in Australian hospitals. Survey data was collected from a sample of healthcare professionals $(n=217)$ working in three hospitals in New South Wales, Australia.

\section{Findings}

Emotional health was the most important personal resource influencing wellbeing, engagement and job satisfaction of nurses, doctors, allied healthcare professionals and managers. The personality characteristic (level of extraversion) influenced job satisfaction but did not show a relationship with wellbeing and engagement. Organisational job resources had a significant influence on wellbeing, engagement and job satisfaction. Of the organisational resources, mentoring and guidance for career progression showed a significant relationship with all three outcomes. Opportunities and facilities for counselling and managing mental fatigue influenced engagement and opportunities, and space for spiritual wellbeing influenced overall wellbeing.

\section{Practical implications}

The findings link human resource management practices to unique motivators of healthcare professionals which in turn are likely to improve engagement, wellbeing and job satisfaction.

\section{Originality/value}

Our study highlights specific resources that support greater levels of wellbeing, engagement and job satisfaction in Australian hospitals.

\section{Keywords}

Work engagement, wellbeing, job satisfaction, healthcare professionals 


\section{Retaining health carers:}

\section{The role of personal and organisation job resources}

\section{Introduction}

The Australian economy faces many challenges in the years to come, one of which being an ageing population. This has been driven, primarily, by increased quality of the healthcare system and individuals living longer, which will lead to a greater allocation of resources to this sector. Thus, a daunting task for Australia will be its ability to retain a skilled healthcare workforce capable of meeting the (rapidly) rising demand for public healthcare services. Public policy has provided additional financial incentives to aid in the recruitment and short-term retention of workers in this sector but has failed to address the longer-term retention of healthcare professionals in regional and rural areas (Buykx et al., 2010). Despite these additional resources, there exists several job specific demands such as shift work, excess workload, and extensive work hours (Danna and Griffin, 1999) that can inhibit the wellbeing, engagement, and job satisfaction of employees in this industry. Further, the psychologically demanding nature of such work can decease engagement (Attridge, 2009) as many healthcare professionals work in environments that threaten their wellbeing (Rechel et al., 2009).

Job demands tend to deplete employees' mental and physical energy, while job resources (mentoring and coaching) aim to mitigate the negative impact of work-related difficulties to achieve work goals and reduce work demands (Bakker and Demerouti, 2007). In fact, the JD-R model can be extended by incorporating personal resources. Personal resources, or traits, provide individuals with a sense of heightened ability to better control their environment (Xanthopoulou et al., 2009). An important implication of the JD-R model is the limited change in motivational potential as a result of decreased job demands and how it is mainly driven by both personal and job resources (Van Wingerden et al., 2017). Thus, in accordance with the JD-R model, this paper examines the influence of personal and organisational resources on work engagement, job satisfaction, and the wellbeing of healthcare professionals in public, regional Australian hospitals. The JD-R model is intentionally used as a theoretical model rather than another model (such as social exchange theory) because the authors are influenced by positive psychology literature which aims for optimal human functioning, focus on developing strengths of employees and the organisation and an help to establish a thriving workplace (Luthans, 2002; Mayers et al., 2013). The focus on flourishing and positive resource building is important for a public hospital system that is already burdened by a hostile and bureaucratic work culture that is driven by the need for achieving cost efficiency. We further extend this paper and determine the key employee and organisational resources that influence work engagement, wellbeing, and job satisfaction of regional healthcare professionals. Thus, we aim to isolate which resources 


\section{Job satisfaction, work engagement and workplace wellbeing in public hospital settings}

Job satisfaction, work engagement and workplace wellbeing are all inter-linked. An employees' job satisfaction are those attitudes and emotions towards certain characteristics of the workplace environment. However, the factors that influence it vary among industries. For instance, Sek and Judge (2009; 1993 cited in Rukh 2015, p. 138) state “... job motivation, involvement, organisational behaviour, job performance, and life satisfaction..." all influence job satisfaction. It has been observed that low job satisfaction is associated with work stressors and low psychological wellbeing (Munir et al., 2012), while increased job satisfaction has a direct effect on work engagement, as observed through improved service delivery and customer orientation (Gountas et al., 2014). This relationship is prevalent in high-pressure, selling oriented industries. Thus, job satisfaction is an important factor that contributes to improved performance in the labour market.

To further extend from job satisfaction, work engagement is a state of mind characterised by positive views to fulfil one's job and consist of three dimensions, namely vigor (high levels of energy, effort, resilience, persistence, and motivation), dedication (involvement in work, enthusiasm, and a sense of pride) and absorption (immersing in one's work) (Schaufeli et al., 2002). Engaged employees work harder, meet customer needs, and are more likely to positively influence financial outcomes (Roberts and Davenport, 2002), while those occupations that are stressful and psychologically demanding can decease engagement (Attridge, 2009), which is a significant issue in the healthcare sector. Effective leadership, workplace relationships, perceived organisational support, working environment, and emotional intelligence all impact one's work engagement (Brunetto et al., 2013) and the availability of these resources can assist with increased engagement levels. As highlighted by Grawitch et al. (2015): "when people possess some control over how they perform their work, they tend to experience more positive wellbeing." (p. 266) This can be a significant issue for public hospital employees due to bureaucracy levels resulting in staff feeling lack of control. With this in mind, work engagement is an important that factor contributing to employee success, which should not be overlooked.

The last facet to consider is wellbeing, which includes a dynamic balance between mental, emotional, physical, spiritual, and social health (McCarthy et al., 2011). In a workplace, wellbeing comprises the presence of optimistic conditions as well as the absence of harmful situations that could lead to stress, depression, and anxiety (Sahu and Rath, 2003). There is a strong connection between the influence of workplace wellbeing and life quality and satisfaction, as well as a link to self-esteem, depression, and anxiety 
(Bassi et al., 2013). Wellbeing at work can be expressed in terms of job meaning, or job significance and importance, and job happiness that captures the affective experience associated with the job (Bassi et al., 2013). Likewise, wellbeing at work is also influenced by work setting, personality traits and occupational stress (De Simone, 2014).

An individuals' satisfaction, wellbeing, and engagement will be influenced by the demands of their occupation, as well as the resources available to alleviate these stresses. The JD-R model (Bakker and Demerouti, 2007; 2014) suggests that job demands are those physical, psychological, social, or organisational aspects of an individual's occupation that require physical and/or psychological effort and are therefore associated with certain physiological and/or psychological costs (Schaufeli and Bakker, 2004). Typically, job demands reduce an employee's mental and physical energy which could lead to health problems (Bakker and Demerouti, 2007) as well as have other spillover effects on job performance. Despite the impact of job demands, which are out of the control of both employers and employees, job resources can be employed to mitigate the effects of the demands for a given occupation. Here, job resources can include those physical, social, or organisational resources that both reduce the demands of employment and the associated physiological and psychological costs, which ensure work goals are achieved, as well as stimulate personal growth (Bakker and Demerouti, 2007; 2008). Thus, it is imperative that these resources are provided to employees to improve job satisfaction, wellbeing, and work engagement.

One aspect to help reduce the pressures of job demands are the organisational resources available to employees - the positive perceptions of human resource (HR) practices may influence employee attitudes and behavioural outcomes (Hutchinson, 2013). Thus, appropriate HR practices should be introduced, as it may provide employees with the sense that the organisation values their contributions and cares for their wellbeing, which will increase positive employee attitudes and behaviour (Hutchinson, 2013). Typically, organisations tend to have stress management, health promotion, and wellness programs, primarily focused on modifying behaviours to address particular health issues or managing existing conditions (McCarthy et al., 2011). Despite this, the effect of HR practices on wellbeing, engagement, and job satisfaction is not automatic. Instead, a positive effect might depend on the effectiveness of HR practices, their implementation, as well as the personal perception of the HR practices by employees (Hutchinson, 2013).

However, an important extension from the traditional JD-R model is the incorporation of personal resources (Xanthopoulou et al., 2007) and the role it plays in the wellbeing, engagement, and satisfaction of employees. With access to the personal resources of an employee, this provides additional information to explain how job resources can be translated into work engagement and job performance (Xanthopoulou et al., 2009), as well as suggest that both the employer and employee should take responsibility for mediating wellbeing. Personal resources refer to an individuals' sense of ability to successfully (and intentionally) influence their environment. Personal resources help to understand an individual's behaviour and the antecedents and consequences of this behaviour. Thus, it is important to incorporate the personal resources 
of an employee into the JD-R model, to help improve the wellbeing, work engagement, and job satisfaction of employees in the labour market.

Researchers note that personality traits influence the extent to which a worker will show indicators of wellbeing (De Simone, 2014) and engagement (Chaudhary et al., 2013). Kinicki (2008) defines personality as "the combination of stable physical and mental characteristics responsible for a person's identity." (p. 46). The 'Big Five' personality traits (extraversion, agreeableness, neuroticism, openness, and conscientiousness) are well-established dimensions to analyse an individual's personality and the impact on other constructs such as wellbeing and engagement. Specific to wellbeing, individuals with a high score on the five personality traits exhibit higher employee wellbeing (Steel, Schmidt and Shultz, 2008). Particular singular personality traits are powerful determinants of wellbeing, as evidenced by the work of Zhai et al., (2013) on extraversion, and in studies on conscientiousness (e.g. Macey and Schneider, 2008; Albuquerque et al., 2014). On the other hand, neuroticism was associated with anxiety, as well as passive and emotion-focus forms of coping and lower wellbeing (DeNeve and Cooper, 1998).

Though studies have identified personality as determinants of engagement (e.g., Inceoglu and Warr, 2011; Wefald et al., 2011), findings have not conclusively determined which personality traits might best predict engagement. This could be due to most research focusing on extraversion, emotional stability and conscientiousness as traits that are by definition linked to engagement (Bakker, Schaufeli, Leiter and Taris, 2008). Some studies perceive openness to experience as a weak predictor of work outcomes (e.g., Griffin and Hesketh, 2004), while Akhtar, Boustani, Tsivrikos and Chamorro-Premuzic, (2015) note openness to experience, extraversion, and conscientiousness are predictors of engagement. Regarding job satisfaction and personality studies, the relationship between personality and job satisfaction was not only important but persisted over time (Judge, Bono and Locke, 2000). Particular personality traits such as extraversion, and conscientiousness were found to positively influence job satisfaction (Judge, Heller and Mount, 2002). On the other hand, neuroticism was negatively associated with and job satisfaction (Maggiori, Johnston and Rossier, 2016).

Further, much research supports the notion that employee's negative emotional states are adversely related to performance and weaken skill acquisition (Koy and Yeo, 2008), with those employees experiencing poor emotional health being less productive, more prone to absenteeism, and have lower overall wellbeing (Danna and Griffin, 1999). From a wellbeing perspective, emotionally healthy staff indicates the existence of positive feelings in employees, which could lead to a happier and more engaged workforce (Harter et al., 2003).

Despite an extensive discussion on the organisational resources in the current literature, limited work has attempted to assess those organisational resources that provide the greatest benefit to employee wellbeing, or those that are most efficient. In this paper we take a 'glass half full' approach to wellbeing 
mainly influenced by positive psychologist such as Seligman who has inspired a movement towards a strengths-based approach (Seligman and Csikczentmihalyi, 2000). Much of the earlier literature seem to focus on the 'illbeing' and focus on burnout and workaholism rather than the positive aspects of wellbeing that focus on resources that support positive impact on wellbeing. Thus, this paper particularly focus on work engagement and job satisfaction which are according to the circumplex model are aligned to pleasure (pleasant feelings) and activation (calm and content state of energy that is reflected in job satisfaction or work engagement that is focused on happy and energised activation levels) (Russell, 1980; Hakanen et al., 2018) rather than unpleasant feelings that result in agitated state (due to workaholism) or dejected and sad feelings (due to burnout). The 'glass half full' state of wellbeing is particularly quite important to cultivate within the public hospitals as burnout and workaholism are both extremely visible in this context.

In the context of public hospitals - as private hospitals differ to their public counterparts in the form of excludability - it is difficult for these hospitals to control job demands, although they do have a direct control on the organisational resources available. Thus, it is imperative to dissect and determine those organisational resources that contribute most to the wellbeing of employees. However, the wellbeing of employees is not (entirely) the responsibility of employers — employees have just as large a role to play in improving wellbeing. By incorporating the 'Big Five' personality traits into the JD-R model, the benefit is twofold. First, the incorporation of these personality traits provides additional information to the JD-R model, as well as help determine those personality traits that contribute or hinder wellbeing. Second, previous research has not employed these personality traits in accordance with the JD-R model. Although the 'Big Five' personality traits are acknowledged as strong dimensions to analyse one's personality, emotional health is another factor that should not be ignored, as it may have negative spillover effects on observable and latent factors such as productivity, absenteeism, and wellbeing. Thus, emotional health will also be analysed to estimate its impact on wellbeing, job satisfaction, and work engagement. Thus, many health workers face their own difficulties. The contribution of this research is to determine which resources (both personal and organisational) can improve the wellbeing, engagement, and job satisfaction of healthcare workers and not focus on why employees experience ill-being.

\section{Data and Methods}

Survey data has been collected from healthcare professionals comprising of nurses, doctors, allied healthcare professionals, and managers in three, small-to-medium, regional public hospitals in New South Wales, Australia between July and December 2014. For confidentiality purposes, the contacted hospitals vary with size, will not be disclosed, and are labelled Hospital D, C, and S accordingly. The senior managers of the local health district were informed of the research project and these three hospitals were first to indicate an interest to participate in the research project. 
To minimise the effect of missing variables, prior to data analysis, the data-set was examined to identify missing responses and irregular entries (Hertel, 1976). Thirty five respondents who did not provide demographic information or provided spurious responses were deleted from the data-set and either mean or mode responses were entered for missing responses. The model estimated and reported is based on 200 total observations, with 166 females and 34 males, no weights, and no missing values in the final data-set, with a majority sample employed as nurses. Further, to minimise the complexities that would ensue from including each survey question in the model, responses were compiled for each group of behavioural and attitude questions into summated scale indices (De Vaus, 2014). Each set of questions were examined to determine the consistency of the application of each response (Likert) scale: convergent construct validity; and internal consistency reliability. Convergent construct validity of each measure was tested by calculating the correlation coefficient between responses on each item with the responses on the set of items that make up the rest of the scale (De Vaus, 2014).

The first outcome variable of interest is observation $i$ 's Workplace Engagement Index (WEI). WEI is a variable that attempts to measure the relative workplace engagement for each respondent. This index is based on the UWES-17, which is sufficient and a clear three-factor model to measure work engagement at work (Bakker and Demerouti, 2008; Schaufeli and Bakker, 2004; 2010). In accordance with the UWES-17 scale, the extent of engagement of work was measured on a seven-point Likert scale from 0 (never) to 6 (always). Examples of items included are: "At my work, I feel bursting with energy;" "I am enthusiastic about my job;" and "I am immersed by my work." The next outcome variable is the Workplace Wellbeing Index (WWI), which is a variable that attempts to measure the relative workplace wellbeing for each observation. It is based on a summated rating scale constructed from 15 questions that relate to workplace wellbeing as measured on a seven-point Likert scale (Page, 2005). Once more, sample questions include: “How much responsibility do you have at work?" and "How meaningful your work is?" The last outcome variable of interest is the Job Satisfaction Index (JSI). This is an index that included a seven-item scale developed by Kofodimos (1993). Sample questions include: "I feel challenged by any work;" and "I have good relations with my co-workers."

To assess the internal consistency, or how closely related a set of items are as a group, a common technique to employ is to observe Cronbach's Alpha, although one can conduct Factor Analysis also. As a rule of thumb, a coefficient above 0.70 is considered to be reliable. Table 1 provides the Cronbach Alpha and the number of items for each index.

\section{Insert Table 1 bere}

One alteration was made to one outcome variable of interest, the WEI. One item recorded a correlation coefficient less than 0.3 and was therefore excluded from the index ("It is difficult to detach myself from my job"). 
The variables of interests correspond to those personal and organisational resources available to employees. The first variables attempt to measure an observation's Emotional Health. The Emotional Health Index (EHI) consists of six questions, measured on a five-point scale, that attempted to measure a respondent's emotional health. Once more, sample questions include: “During the past four weeks how much have you felt calm and peaceful?" and "During the past four weeks, did you have a lot of energy?" Missing responses for emotional health questions were replaced with median responses. Second, the personality inventory (PI) exploits questions from John et al. (1991) and John et al. (2008)'s big-five inventory. It is a 44-item list that measures an individual on five dimensions of personality, using a fivepoint scale. Each factor is divided into personality facets. Approximately one-third of the questions are reported on a reverse scale. Questions for each personality trait were grouped together and responses were assessed to ensure they were positively correlated. The Agreeableness-Antagonism Index (PAI) measure includes nine questions such as: "Is (not) cold and aloof;" and "Likes to compete with others." Further, the Conscientiousness-Lack of Direction Index (PCI) was created from nine questions that include: "Is not (somewhat) careless;" and "Does not tend to be dis-organised." Following, the Extraversion-Introversion Index (PEI) is created from eight questions that ask: "Has an assertive personality;" and "Is full of energy." The Openness-Closed to Experience Index (POI) includes ten questions that ask if the respondent is sophisticated in art, music, or literature, as well as if they have any artistic interests. The last personal resource observed is the Neuroticism-Emotional Stability Index (PNI). The index was created from ten questions that asked if the respondent remains calm in tense situations and if the respondent was depressed. The last variable of interest, attempting to explain the influence or organisational resources, is a Human Resources Index (HRI). HRI included nine questions targeting HR practices and resource allocation for ongoing staff training and development, monetary reward systems, mentoring and guidance for career progression, opportunities and facilities for physical activity and roster breaks, opportunities and facilities for counselling and managing mental fatigue, opportunities and facilities for social wellbeing and spiritual wellbeing of employees which were all measured on an identical five-point scale. The nine questions were developed after consultation with HR professionals and line managers at the public hospital about context specific wellbeing challenges facing the public hospital system and literature on positive psychology and JD-R model. For example, job resources as per JD-R model includes the physical, psychological, social and organisational conditions which help to achieve work goals, reduce the demands of work (which are particularly high in for publicly funded hospitals), and stimulate personal growth and development (Van den Broeck et al., 2016).

Similar to the outcome variables, an internal consistency test was conducted in accordance with Cronbach's Alpha. Table 2 summarises this information with respect to each variable of interest:

Insert Table 2 bere 
This study investigates the relationship between three dependent measures, workplace engagement, workplace wellbeing, and job satisfaction, on specific personal and organisational resources, conditional on demographic characteristics and contextual factors. When estimating a relationship between two or more groups with several independent variables, there are two testing options: separate analysis of variance tests for each outcome variable; or a multiple analysis of variance test that simultaneously measures differences in each dependent variable. The former approach increases the Type I error risk, showing relationships between independent and dependent variables that may not actually exist (Stevens 2012). Here, a multiple analysis of covariance (MANCOVA) estimation strategy is used to estimate the relationship. Between the three outcome measures, the variables of interest, and covariates, which are both continuous and factors, the following relationship will be estimated:

$$
\left.\begin{array}{c}
W E I_{i} \\
W W I_{i} \\
J S I_{i}
\end{array}\right\}=\alpha+\beta_{1} E H I_{i}+\beta_{2} P I_{i}+\beta_{3} P A I_{i}+\beta_{4} P C I_{i}+\beta_{5} P E I_{i}+\beta_{6} P O I_{i}+\beta_{7} P N I_{i}+\beta_{8} H R I_{i}+\gamma X_{i}^{\prime}+u_{i}
$$

The outcome variables are indices for work engagement, workplace wellbeing, and job satisfaction. The variables of interest are those associated with the coefficients from $\beta_{1}$ to $\beta_{8}$. The first seven variables represent different aspects of the respondent's personal resources, while the last variable is a measure of the organisational resources available to the employee. $X$ represents a vector of the covariates (age, gender, 
culture, contextual factors and occupation) for observation $i$, included to ensure there is no correlation between the residual and the variables of interest. Last, $u$ is the residual, representing additional factors that may have an effect on our outcome variables, but are not introduced in the model.

To justify the use of a MANCOVA estimation strategy, it is important to observe the correlations between both regressands and regressors. Bivariate relationships between the variables, using Pearson correlations for the scale variables and Kendall's Tau and Spearman correlations for the nominal data (Taylor, 2011) are observed. The independent variables are moderately correlated, with significant correlations for the factor variables up to 0.207 and for the scale variables up to 0.527 in absolute terms. The dependent variables are significantly correlated with each other, from 0.549 to 0.767 . Thus, this suggests that a multi-variate approach is necessary. The purpose of the study was to assess which personal and organisational resources influenced wellbeing, engagement and job satisfaction. To this end we directed the study to measure these three constructs separately, to pin point which personal and organisational resources clearly influenced which constructs. In doing so, we can provide more specific guidance about which resources could be activated to influence wellbeing, engagement and job satisfaction. We acknowledge the correlation among the dependent variables are worthy of future exploration and may be considered as a limitation given the scope of this study.

The credibility of this technique relies on the satisfaction of the homogeneity, normality, and multicollinearity assumptions. Two tests for homogeneity have been used. First, Box's test of the equality of the covariance matrices over group tests whether the correlations between the dependent variables and the standard deviations are similar over groups (Ho, 2014). Here, the Box test is insignificant, so the assumption of equality of covariance matrices has not been violated. Second, Levene's test of equality of error variances tests whether the variance of each dependent variables varies significantly over groups (Taylor, 2011). This test result is insignificant for all independent variables - homogeneity of variance is a valid assumption. The second assumption to ensure credibility is normality. To test the normality of the distributions of the dependent variables, the Kolmogorove-Smirnov and Shapiro-Wilk tests were used (Taylor, 2011). For the nominal variables, a number of sub-categories tested as non-normal. However, this is likely to be only marginally significant, as the sample size is relatively small. The histograms are approximately bell-shaped, and the normal-normal plots show points falling fairly close to their central line (Ho, 2014; Taylor, 2011). The final assumption that needs to be satisfied is multicollinearity. The association between all explanatory variables and the dependent variables is not strong, which suggests multicollinearity is not an influence within the data-set. To test for multicollinearity, the variance inflation factor (VIF) for each scale variable was calculated for each separate univariate regression model. For all three dependent variables, the VIF was less than two for all indices except for the PEI, which was 2.131, well below the multicollinearity threshold of 10 (Ho 2014). Last, it should be stressed that Pillai's criterion (1955) was used as the multivariate statistic, as some of the group sizes for some explanatory variables were small and unequal. Further, this criterion is more robust than the more commonly-used Wilks' Lambda (1932). 


\section{Results}

Of the personality factors observed, the level of extraversion-introversion (PEI) had an influence on the outcomes of interest. PEI has a significant effect on JSI, but not with WEI or WWI, and contributes up to 0.121 of the value of JSI. Emotional Health of the health professional (EHI) has a strong positive association with all dependent variables, contributing up to 0.192 of the value of WEI, 0.333 of WWI and 0.321 of JSI. To identify which elements of the EHI had the greatest influence, MANOVA analysis was conducted to estimate the relationship between WEI, WWI and JSI, and the six emotional questions, treated as ordinal variables. The multi-variate test statistics (Wilks' Lambda, $\mathrm{F}<0.05$ ) point to a significant relationship between the dependent variables and having a lot of energy and resisting expressing their true feelings. Examining the between subjects' tests and the parameter estimates also reveals that respondents who were more likely to agree that they felt calm and peaceful, on average, reported higher levels of WWI and JSL. Further, those respondents that had a lot of energy, on average, reported higher levels of WEI, WWI, and JSL. Last, those that resist expressing their true feelings reported higher levels of JSI.

The Human Resource practices (HRI) has a significant relationship with WEI, WWI and JSI. HRI also has a positive relationship with all three dependent variables, contributing up to 0.095 of the value of WEI, 0.373 of WWI and 0.212 of JSI. To identify which elements of HRI had the greatest influence we conducted, a MANOVA analysis of the relationship between the three dependent variables, WEI, WWI and JSI, and the eight human resources questions, treated as ordinal variables, similar to that conducted for the EHI variable. The multivariate test statistics (Wilk's Lambda, $\mathrm{F}<0.05$ ) point to a significant relationship between opportunities and space for counselling and managing mental fatigue and for spiritual wellbeing of employees (e.g. meditation, prayer space) and WEI, WWI and JSI. Resources for mentoring and guidance for career progression also appears to be significant at the 0.10 level.

The parameter estimates also reveals that resources for mentoring and guidance for career progression has a significant relationship with JSI at the 0.05 level. It also has a significant relationship with both WEI and WWI at the 0.10 level. On average, respondents reporting higher levels of resources for mentoring and guidance also reported higher WEI, WWI and JSI. Furthermore, opportunities and facilities for counselling and managing mental fatigue has a significant relationship with WEI at the 0.05 level. On average, respondents reporting higher levels of opportunities and facilities for counselling and managing mental fatigue reported higher levels of WEI. Lastly, opportunities and space for spiritual wellbeing of employees has a significant relationship with WWI at the 0.05 level. On average, respondents reporting higher levels of opportunities and space for spiritual wellbeing of employees reported higher levels of WWI.

Although not of upmost importance with respect to this study, interesting findings can be observed when one focuses on covariates. The hospital itself had a significant relationship with JSI, but not with WEI or WWI. The job satisfaction index for employees at Hospital C was on average 0.082 lower than 
employees employed in the other surveyed hospitals. Similarly, Culture (CUL) had a significant relationship with WEI at the 0.05 level, and WWI at the 0.10 level, with people describing themselves as being from 'other Western countries' reporting lower levels of WEI and WWI than people describing themselves as Australian or from other countries. Similarly, the personality/narcissism index (PNI) had a significant relationship with WWI at the 0.05 level, reducing the overall value of WWI by as much as 0.318 . For Hospital S, only Emotional Health (EHI) had a significant multivariate statistic. EHI was significant at the 0.05 level for all three dependent variables, contributing up to 0.238 of the value of WEI, 0.426 of WWI and 0.338 of JSI. The sample of 23 respondents from Hospital D was too small for robust analysis.

\section{Discussion}

The study examines the extent personal resources (as measured by the 'Big Five' and emotional health) and organisational job resources (HR practices) influence the workplace engagement, job satisfaction, and wellbeing of regional healthcare professionals in Australian public hospitals. The JD-R model (Bakker and Demerouti, 2014) has been used as the basis due to its relevance to regional healthcare professionals, as there are increasing trends that indicate the longer-term retention of healthcare professionals in the regional and rural areas is a concern. The intense job demands of the profession, bureaucracies, lack of resourcing in the public healthcare system, isolation, and lack of career progression and support in these regional areas can all have a negative influence on the wellbeing, engagement, and job satisfaction of employees. Despite the significance of the JD-R model, an important extension to this model is the assimilation of personal resources and the role it plays in the wellbeing, engagement, and satisfaction of employees (Xanthopoulou et al., 2007). Having the ability to observe the personal resources of an employee provides additional information to explain how job resources can be translated into work engagement and job performance (Xanthopoulou et al., 2009). Another important implication of adding personal resources to the analysis is the emphasis it places on the responsibility of employees (in conjunction with employers) to mediate wellbeing. The current literature focuses on the leadership aspects of organisational resources. However, an emphasis must be placed on those resources (both personal and organisational) that contribute to - or hinder — the wellbeing of employees in the healthcare sector. The study aimed to understand the significant relationships between personal and organisational resources that can support the wellbeing, engagement, and job satisfaction of regional healthcare professionals.

Personal resources (personality characteristics and emotional health) have a significant and varied influence on the wellbeing, engagement, and job satisfaction of regional healthcare employees. The empirical results of this study confirm the importance of the emotional health of employees on their wellbeing and concur with existing research to note that employees with higher levels of emotional health would have more positive emotions and social interactions, and thus exhibit higher levels of wellbeing at work (De Simone, 2014; Danna and Griffin, 1999). The study uncovers certain aspects of emotional health that can influence a range of employee outcomes. For instance, when healthcare professionals felt calm and 
peaceful, they reported higher levels of WWI and JSI. Although as per Bakker and Oerlemans (2011) and Russell (1980), the circumplex model of affect notes that feelings of calmness is more associated with job satisfaction while feelings of energy is associated with work engagement, health professionals in this study who display higher energy levels reported higher levels of WWI, WEI, and JSI. Thus, it is important to understand how and why different aspects of emotional health may influence WWI, WEI, and JSI.

Although the EHI included six constructs, only three of the constructs had a significant influence. Feeling down hearted, emotionally drained, and pretending to have emotions that they do not have did not have an influence on WWI, WEI, and JSI. Evidently, positive constructs of emotional health (i.e. energy and being calm) had a greater impact on WEI, WWI, and JSI than the other more negative constructs of emotional health. Particularly, the level of energy had a significant influence on all three outcomes. Thus, it seems that energy levels can positively influence all three outcomes. It seems that activation of energy may help healthcare workers to cope with the job demands more than calmness. As such it is possible that high activation based state should be encouraged within work environments that are generally characterised by shift work and long hours of challenging work environments. The implication of this finding is that a focus on how senior management and HR divisions could cultivate this emotional characteristic more in their healthcare professionals, which may yield greater results. Perhaps having energy is an important emotional health check that could be embedded into recruitment and career progression processes in the public health sector.

Although existing research notes that suppressing one's true emotions is negatively linked with job satisfaction (Yang and Chang, 2008), our findings indicate that healthcare workers who resist expressing true feelings reported higher levels of job satisfaction. This may be due to the nature of the profession. Regional healthcare workers are frequently challenged by ethical and social dilemmas when servicing patients (Joza, 2013). For instance, a clinician with opinions about abortion or euthanasia threatening unbiased professional judgement and service to a patient will negatively affect WWI, WEI and JSI.

Notably, long term resistance to one's true feelings may negatively affect one's overall wellbeing. Thus, it is important that healthcare workers continuously practice the art of debriefing within a multi-disciplinary group on a daily basis. Although debriefing can generally have many positive impacts such as mentoring and learning with each experience (Drury et al., 2014), it is possible that many healthcare workers do not regularly practice debriefing. Some reasons for not debriefing include time constraints, judging, bullying, blaming and isolating the mindset observed within the public health care system, bureaucracies in terms of established routines, and the management approach of the senior consultants/management in a hospital.

Finally, the Big Five personality traits were incorporated into the analysis to dissect personal resources, as well as estimate which of the five traits contribute to the wellbeing, engagement, and job satisfaction of regional healthcare professionals. Out of the five personality traits, only one aspect of personality 
(extraversion) had a significant influence on JSI. Extraverts tend to be outgoing, like to take charge and try to change things within the work environment to suit their needs (Howard and Howard, 2001). Of the 7 questions under JSI, three of the questions involve assessment of whether the participant agrees to have good relationships with co-workers, have fun at work, and get recognised and respected at work. These questions align to extraversion; outgoing, sociable, and talkative. Thus, it is not surprising that extraversion contributed positively to JSI. However, it is not clear why other positive personality characteristics (i.e. being open to new experiences and agreeableness) did not positively influence the WWI and WEI of the regional healthcare workers and is the focus of future research.

An important factor contributing to the wellbeing, engagement, and job satisfaction of employees are the organisational resources available. Most employers are able to have a direct influence on the resources provided to employees but have little authority over the demands of the job. HR practices can positively influence the WWI, WEI and JSI by acting as a caravan passageway for the organisation to foster environmental conditions that support, and enrich the personal resources of regional healthcare workers and minimise the job demands that impoverish their resource reservoirs (Hobfoll, 2012). The HRI index included 8 questions around organisational resourcing of training and development, mentoring, facilities for physical activities, counselling, social wellbeing, spiritual wellbeing, monetary, and non-monetary rewards. The findings align with the previous literature (Hayward, 2010; Kular et al., 2008) in how organisational support systems can facilitate employees to accomplish the full ability to perform and consequently enhance WWI, WEI and JSI. However, aspects of organisational resourcing (HR practices) influence regional healthcare workers' WWI, WEI and JSI differently. The findings presented indicate that, on average, regional healthcare workers who indicate they experience higher levels of resources for mentoring and guidance reported higher levels of WWI, WEI and JSI, other HR practices, did not have a similar impact on all three aspects. For instance, regional healthcare workers who reported higher levels of opportunities for spiritual wellbeing only reported higher levels of WWI, while healthcare workers who reported higher levels of opportunities for counselling and managing mental fatigue only reported higher levels of WWI.

Extant literature has focussed on how training and development, monetary and non-monetary rewards can increase engagement and job satisfaction (e.g. Hulkko-Nyman et al., 2012; Haider et al., 2015). Mentoring and guidance for career progression can support wellbeing, engagement and job satisfaction. However, little research has examined how other job resources such as counselling and resourcing for spiritual wellbeing influence employee wellbeing, engagement and job satisfaction. The findings presented specify those resources that support greater levels of wellbeing, engagement and job satisfaction in regional public hospitals. However, what is not known is how job resources allocated to spiritual wellbeing and counselling aimed at mental fatigue management can support engagement and wellbeing of healthcare professionals, particularly of regional healthcare workers. Senior managers at public hospitals would need to explore how resources are allocated to spiritual wellbeing and managing mental fatigue, particularly as 
the complexity and demands of the profession affect retention of skilled healthcare workers in regional areas. This effect is especially nascent in bureaucratic systems with traditional management styles embedded in the organisation that are difficult to change. Change can only occur if and when leadership of such public institutes are willing to change, understand the need for change and adapt their leadership style and restructure the organisation to support the long-term wellbeing, engagement and job satisfaction amongst the healthcare professionals. Such measures will facilitate employees to understand the importance of organisational resources to achieve personal goals and comprehend how practices and systems are linked to intrinsic motivations (Buetow, 2007).

\section{Conclusion}

This research aims to understand the key personal and organisational resources that influence the engagement, wellbeing and job satisfaction of healthcare professionals working in regional hospitals in Australia. The findings indicate various personal resources and organisational resources influence wellbeing, engagement and job satisfaction in different ways. For example, the emotional health of healthcare professionals influences the wellbeing and engagement while the only personality characteristic to positively influence job satisfaction is extraversion. An important personal resource is energy level and has an influence on wellbeing, engagement and job satisfaction. The most significant organisational resource was mentoring and guidance on career progression which positively influenced wellbeing, engagement and job satisfaction. Opportunities for spiritual wellbeing influenced wellbeing while opportunities and facilities for counselling and managing mental fatigue influenced engagement levels. The findings of the study can support leaders at public hospitals to allocate organisational resources in a more meaningful manner to facilitate higher levels of retention and engage a skilled healthcare workforce in regional areas in the future.

Although this study has some limitations, these limitations provide opportunities for future research. Firstly, the findings may not be relevant beyond the health sector. The study was limited to healthcare professionals in three regional public hospitals in New South Wales, Australia. Future research could examine these findings more in depth and expand the research to larger hospitals in Australia. Secondly, the research captures a snapshot of the variables in action in hospital settings. Longitudinal studies could help uncover time-based effects on study variables. Thirdly, this study is based on self-reported measures. Future research could also assess how managers' and patients evaluate the performance of the health care workforce. 


\section{References}

Akhtar, R., Boustani, L., Tsivrikos, D., and Chamorro-Premuzic, T. (2015), "The engageable personality: Personality and trait EI as predictors of work engagement”. Personality and Individual Differences, Vol. 73, pp. 44-49.

Albuquerque, I., De Lima, M. P., Matos, M. and Figueiredo, C. (2014), "Work matters: Work personal projects and the idiosyncratic linkages between traits, eudaimonic and hedonic well-being", Social Indicators Research, Vol. 115 No. 2, pp. 885-906.

Attridge, M. (2009), "Measuring and managing employee work engagement: A review of the research and business literature", Journal of Workplace Behavioral Health, Vol. 24 No. 4, pp. 383-398.

Bakker, A.B. and Demerouti, E. (2007), “The job demands-resources model: State of the art", Journal of managerial psychology, Vol. 22 No. 3, pp. 309-328.

Bakker, A.B. and Demerouti, E. (2008), "Towards a model of work engagement", Career development international, Vol. 13 No. 3, pp. 209-223.

Bakker, A. B., Schaufeli, W. B., Leiter, M. P., and Taris, T. W. (2008). "Work engagement: An emerging concept in occupational health psychology”. Work \& Stress, Vol. 22 No. 3, pp. 187-200.

Bakker, A.B. and Demerouti, E. (2014), "Job demands-resources theory: Taking stock and looking forward", Journal of Occupational Health Psyhology, Vol. 22 No. 3, pp. 273-285.

Bassi, M., Bacher, G., Negri, L. and Delle Fave, A. (2013), "The contribution of job happiness and job meaning to the well-being of workers from thriving and failing companies" Applied Research in Quality of Life, Vol. 8 No. 4, pp. 427-448.

Brunetto, Y., Xerri, M., Shriberg, A., Farr-Wharton, R., Shacklock, K., Newman, S. and Dienger, J. (2013), "The impact of workplace relationships on engagement, well-being, commitment and turnover for nurses in Australia and the USA", Journal of Advanced Nursing, Vol. 69 No. 12, pp. 2786-2799.

Buetow, S. (2007), "What motivates health professionals? Opportunities to gain greater insight from theory", Journal of Health Services Research and Policy, Vol. 12 No. 3, pp. 183-185.

Buykx, P., Humphreys, J., Wakerman, J. and Pashen, D. (2010), "Systematic review of effective retention incentives for health workers in rural and remote areas: Towards evidence-based policy", Australian Journal of Rural Health, Vol. 18 No. 3, pp. 102-109. 
Chaudhary, R., Rangnekar, S. and Barua, M.K. (2013), "Engaged versus disengaged: The role of occupational self-efficacy", Asian Academy of Management Journal, Vol. 18 No.1, pp. 91-108.

Danna, K. and Griffin, R.W. (1999), "Health and well-being in the workplace: A review and synthesis of the literature", Journal of Management, Vol. 25 No. 3, pp. 357-384.

De Simone, S. (2014), "Conceptualizing wellbeing in the workplace" International Journal of Business and Social Science, Vol. 5 No. 12, pp. 118-122.

De Vaus, D.A. (2014), Surveys in Social Research, Allen and Unwin, Sydney, NSW.

Deneve, K.M. and Cooper, H. (1998), “The happy personality: A meta-analysis of 137 personality traits and subjective well-being”, Psychological Bulletin, Vol. 124 No. 2, pp. 197-229.

Gountas, S., Gountas, J. and Mavondo, F.T. (2014), "Exploring the associations between standards for service delivery (organisational culture), co-worker support, self-efficacy, job satisfaction and customer orientation in the real estate industry", Australian Journal of Management, Vol. 39 No. 1, pp. 107-126.

Grawitch, M.J., Ballard, D.W. and Erb, K.R. (2015), “To be or not to be (stressed): The critical role of a psychologically healthy workplace in effective stress management”, Stress and Health, Vol. 31 No. 4, pp. 264273.

Griffin, B. and Hesketh, B. (2004), "Why openness to experience is not a good predictor of job performance", International Journal of Selection and Assessment, Vol. 12, pp. 243-251.

Haider, M., Aamir, A., Hamid, A.A. and Hashim, M. (2015), “A literature analysis on the importance of non-financial rewards for employees' job satisfaction", Abasyn Journal of Social Sciences, Vol. 8 No. 2, pp. 341 354.

Hakanen, J., Peeters, M., and Schaufeli, W. (2018), "Different types of employee well-being across time and their relationships with job crafting”, Journal of Occupational Health Psychology, Vol. 23 No. 2, pp. $289-301$.

Harter, J.K., Schmidt, F.L. and Keyes, C.L.M. (2003), "Well-being in the workplace and its relationship to business outcomes: A review of the Gallup studies", in Keyes, C.L.M. and Haidt, J. (Eds.), Flourishing: Positive psychology and the life well-lived, American Psychology Association, Washingtong DC, pp. 205-224.

Hayward, S. (2010), "Engaging employees through whole leadership”, Strategic HR Review, Vol. 9 No. 3, pp. $11-17$.

Hertel, B.R. (1976), "Minimizing error variance introduced by missing data routines in survey analysis", Sociological Methods and Research, Vol. 4 No. 4, pp. 459-474. 
Ho, R. (2014), Handbook of univariate and multivariate data analysis with IBM statistics, Taylor \& Francis Group, Boca-Raton, FL.

Hobfoll, S. (2012), “Conservation of Resources and Disaster in Cultural Context: The Caravans and Passageways for Resources", Psychiatry: Interpersonal and Biological Processes, Vol. 75 No. 3, pp. 227-232.

Howard, P.J. and Howard, J.M. (2001), The owner's manual for personality at work: How the big five personality traits affect performance, communication, teamwork, leadership, sales, Bard Press, Austin, TX.

Hulkko-Nyman, K., Sarti, D., Hakonen, A. and Sweins, C. (2012), “Total Rewards Perceptions and Work Engagement in Elder-Care Organizations: Findings from Finland and Italy", International Studies of Management \& Organization, Vol. 42 No. 1, pp. 24-49.

Hutchinson, S. (2013), Performance management: theory and practice, The Chartered Institute of Personnel and Development, London.

Inceoglu, I. and Warr, P. (2011), "Personality and job engagement". Journal of Personnel Psychology, Vol. 10 No. 4, pp. 177-181.

John, O.P., Donahue, E.M. and Kentle, R.L. (1991), The big five inventory: Versions 4a and 54, Institute of Personality and Social Science Research, University of California, Berkeley, CA.

John, O.P., Naumann, L.P. and Soto, C.J. (2008), "Paradigm shift to the integrative big five trait taxonomy", Handbook of personality: Theory and research, Vol. 3 No. 2, pp. 114-158.

Joza, J.A. (2013), A Grounded Theory Study of the Approaches and Mechanisms Used in Public Health Practice for Everyday Ethical Dilemma Negotiation and Resolution (Doctoral Dissertation).

Judge, T. A., Bono, J. E. and Locke, E. A. (2000), "Personality and job satisfaction: The mediating role of job characteristics". Journal of Applied Psychology, Vol. 85 No. 2, pp. 237-249.

Kinicki, A. (2008), Organisational behaviour: Core concepts, McGraw-Hill, New York, NY.

Kofodimos, J.R. (1993), Balancing act: How managers can integrate successful careers and fulfilling personal lives, JosseyBass, San Francisco, CA.

Koy, A. and Yeo, G. (2008), "BIS sensitivity, negative affect and performance: Dynamic and multilevel relationships" Human Performance, Vol. 21 No. 2, pp. 198-225.

Kular, S., Gatenby, M., Rees, C., Soane, E. and Truss, K. (2008), "Employee engagement: A literature review”, working paper [19], Kingston Business School, Kingston University, Available: eprints.kingston.ac.uk/4192/1/19wempen.pdf. 
Luthans, F. (2002), "The Need for and Meaning of Positive Organizational Behavior", Journal of Organizational Behavior, Vol. 23 No. 6, pp. 695-706.

Macey, W.H. and Schneider, B. (2008), “The meaning of employee engagement”, Industrial and organizational Psychology, Vol. 1 No. 1, pp. 3-30.

\section{Maggiori, C., Johnston, C. S., and Rossier, J. (2016), "Contribution of personality, job strain, and occupational self-efficacy to job satisfaction in different occupational contexts". Journal of Career Development, Vol. 43 No. 3, pp. 244-259.}

Meyers, M., van Woerkom, M. and Bakker, A. (2013), “The added value of the positive: A literature review of positive psychology interventions in organizations", European Journal of Work and Organizational Psychology, Vol. 22 No. 5, pp. 618-32.

Mccarthy, G., Almeida, S. and Ahrens, J. (2011), "Understanding Employee Well-Being Practices in Australian Organizations", International Journal of Health, Wellness and Society, Vol. 1 No. 1, pp. 181-197.

Munir, F., Nielsen, K., Garde, A.H., Albertsen, K. and Carneiro, I.G. (2012), "Mediating the effects of work-life conflict between transformational leadership and health-care workers' job satisfaction and psychological wellbeing", Journal of Nursing Management, Vol. 20 No. 4, pp. 512-521.

Page, K. (2005), "Subjective wellbeing in the workplace”, Unpublished honours thesis, Deakin University, Burwood, Melbourne, Australia.

Rechel, B., Buchan, J. and Mckee, M. (2009), “The impact of health facilities on healthcare workers' wellbeing and performance", International Journal of Nursing Studies, Vol. 46 No. 7, pp. 1025-1034.

Roberts, D.R. and Davenport, T.O. (2002), "Job engagement: Why it's important and how to improve it", Employment Relations Today (Wiley), Vol. 29 No. 3, pp. 21-29.

Rukh, L., Choudhary, M.A. and Abbasi, S.A. (2015), "Analysis of factors affecting employee satisfaction: A case study from Pakistan", Work, Vol. 52 No. 1, pp. 137-152.

Russell, J. (1980), “A circumplex model of affect”, Journal of Personality and Social Psychology, Vol. 39 No. 6, pp. 1161-1178.

Sahu, F.M. and Rath, S. (2003), "Self-efficacy and wellbeing in working and non-working women: The moderating role of involvement", Psychology and Developing Societies, Vol. 15 No. 2, pp. 187-200.

Schaufeli, W. and Bakker, A.B. (2010), "The conceptualization and measurement of work engagement", in Bakker, A.B. and Leiter, M.P. (Ed.), Work engagement: A handbook of essential theory and research, Psychology Press, New York, NY, pp. 10-24. 
Schaufeli, W.B. and Bakker, A.B. (2004), "Job demands, job resources, and their relationship with burnout and engagement: A multi-sample study", Journal of Organizational Behavior, Vol. 25 No. 3, pp. 293-315.

Schaufeli, W.B., Salanova, M., González-Romá, V. and Bakker, A.B. (2002), “The measurement of engagement and burnout: A two sample confirmatory factor analytic approach", Journal of Happiness Studies, Vol. 3 No. 1, pp. 71-92.

Seligman, M.E.P. and Csikszentmihalyi, M. (2000), "Positive Psychology: An Introduction", in Csikszentmihalyi, M. (Ed.), Flow and the Foundations of Positive Psychology, Springer, Dordrecht, GX, pp. 279298.

Steel, P., Schmidt, J. and Shultz, J. (2008), "Refining the relationship between personality and subjective well-being”. Psychological Bulletin, Vol. 134, pp. 138-161.

Stevens, J.P. (2012), Applied multivariate statistics for the social sciences, Lawrence Erlbaum Associates Inc., Mahwah, NJ.

Taylor, A. (2011), Multivariate Analyses with manova and GLM, Department of Psychology, Macquarie University, Available:

https: / $/$ www.google.com.au/ url?sa $=\mathrm{t} \& \mathrm{rct}=\mathrm{j} \& \mathrm{q}=\&$ esrc $=\mathrm{s} \&$ source $=$ web\&cd $=1 \& \mathrm{ved}=0 \mathrm{ahUKEwjv1}$ JnLl bXVAhWMTLwKHaJVDM8QFggvMAA\&url=http\%3A\%2F\%2Fpsy.mq.edu.au\%2Fpsystat $\% 2$ Fdocum ents $\% 2 F M u l t i v a r i a t e . p d f \& u s g=A F Q j C N G O d W N a 129 t t u 5 i s 42 \mathrm{hMd} 611 \mathrm{r} 2 \mathrm{vOw}$ [Accessed 10 January 2017 ].

Van den Heuvel, M., Demerouti, E. and Peeters, M. (2015), “The job crafting intervention: effects on job resources, self-efficacy, and affective well-being", Journal of Occupational and Organizational Psychology, Vol. 88 No. 3, pp. 511-532.

Van Wingerden, J., Bakker, A.B. and Derks, D. (2017), "Fostering employee well-being via a job crafting intervention", Journal of Vocational Behavior, Vol. 100, pp. 164-174.

Wefald, A. J., Reichard, R. J. and Serrano, S. A. (2011), "Fitting engagement into a nomological network: The relationship of engagement to leadership and personality". Journal of Leadership \& Organizational Studies, Vol. 18 No. 4, pp. 522-537.

Xanthopoulou, D., Bakker, A.B., Demerouti, E. and Schaufeli, W.B. (2007), “"The role of personal resources in the job demands-resources model”, International Journal of Stress Management, Vol. 14 No. 2, pp. 121-141.

Xanthopoulou, D., Bakker, A.B., Demerouti, E. and Schaufeli, W.B. (2009), "Reciprocal relationships between job resources, personal resources, and work engagement", Journal of Vocational behavior, Vol. 74 No. 3, pp. 235-244. 
Yang, F.H. and Chang, C.C. (2008), "Emotional labour, job satisfaction and organizational commitment amongst clinical nurses: A questionnaire survey", International Journal of Nursing Studies, Vol. 45 No. 6, pp. 879-887.

Zhai, Q., Willis, M., O'shea, B., Zhai, Y. and Yang, Y. (2013), "Big Five personality traits, job satisfaction and subjective wellbeing in China" International Journal of Psychology, Vol. 48 No. 6, pp. 1099-1108. 
Table 1: Internal Consistency Tests for Outcome Variables

\begin{tabular}{lll}
\hline & $\begin{array}{l}\text { Cronbach's } \\
\text { Alpha }\end{array}$ & $\begin{array}{l}\text { Number of } \\
\text { Items }\end{array}$ \\
\hline $\begin{array}{l}\text { Workplace Engagement Index } \\
\text { (WEI) }\end{array}$ & 0.91 & 16 \\
\hline $\begin{array}{l}\text { Workplace Wellbeing Index } \\
\text { (WWI) }\end{array}$ & 0.93 & 15 \\
\hline Job Satisfaction Index (JSI) & 0.82 & 7 \\
\hline
\end{tabular}

Table 2: Internal Consistency Test for Variables of Interest

\begin{tabular}{lll}
\hline & $\begin{array}{l}\text { Cronbach's } \\
\text { Alpha }\end{array}$ & $\begin{array}{l}\text { Number of } \\
\text { Items }\end{array}$ \\
\hline Emotional Health Index (EHI) & 0.693 & 6 \\
[Personal Resource] & & 9 \\
\hline Agreeableness-Antagonism & 0.737 & \\
Index (PAI) [Personal & & 9 \\
Resource] & & \\
\hline Conscientiousness-Lack of & 0.758 & 8 \\
Direction Index (PCI) [Personal & & \\
Resource] & & 10 \\
\hline Extraversion-Introversion Index & 0.833 & \\
(PEI) [Personal Resource] & & \\
\hline Openness-Closed to Experience & 0.753 & \\
Index (POI) [Personal & & \\
Resource] & & \\
\hline Neuroticism-Emotional Stability & 0.811 & \\
Index (PNI) [Personal & & \\
Resource] & & \\
\hline Human Resources Index (HRI) & 0.856 & \\
[Organisational Resource] & & \\
\hline
\end{tabular}


Table 3: Descriptive Statistics

\begin{tabular}{|c|c|c|c|c|c|c|}
\hline & & Count & Minimum & Maximum & Mean & Std Dev \\
\hline Workplace Wellbeing Index & & 200 & 0.19 & 0.99 & 0.6767 & 0.1839 \\
\hline Workplace Engagement Index & & 200 & 0.25 & 0.94 & 0.6477 & 0.1329 \\
\hline Job Satisfaction Index & & 200 & 0.39 & 1.00 & 0.7552 & 0.1566 \\
\hline Age in years & & 200 & 20 & 63 & 43.570 & 12.2460 \\
\hline Gender & $\begin{array}{l}\text { Female } \\
\text { Male }\end{array}$ & $\begin{array}{c}168 \\
34\end{array}$ & & & & \\
\hline $\begin{array}{l}\text { Reported any health } \\
\text { conditions }\end{array}$ & $\begin{array}{l}\text { No } \\
\text { Yes }\end{array}$ & $\begin{array}{l}92 \\
111\end{array}$ & & & & \\
\hline Cultural orientation & $\begin{array}{l}\text { Australian } \\
\text { Other western } \\
\text { country } \\
\text { Other }\end{array}$ & $\begin{array}{c}168 \\
14 \\
\\
21\end{array}$ & & & & \\
\hline Hospital & $\begin{array}{l}\text { D } \\
\text { C } \\
\text { S }\end{array}$ & $\begin{array}{c}30 \\
96 \\
106\end{array}$ & & & & \\
\hline Employment status & $\begin{array}{l}\text { Permanent FT } \\
\text { Permanent PT } \\
\text { Contract \& casual }\end{array}$ & $\begin{array}{l}88 \\
77 \\
38 \\
\end{array}$ & & & & \\
\hline Occupation & $\begin{array}{l}\text { Nursing } \\
\text { Allied health } \\
\text { Doctor } \\
\text { Management } \\
\text { Other }\end{array}$ & $\begin{array}{c}114 \\
31 \\
20 \\
4 \\
34\end{array}$ & & & & \\
\hline Years in this organisation & & 200 & 0.50 & 22.00 & 7.3779 & 6.9003 \\
\hline Emotional Health Index & & 200 & 0.13 & 0.92 & 0.5396 & 0.1669 \\
\hline Human Resources Index & & 200 & 0.00 & 0.97 & 0.4336 & 0.2164 \\
\hline $\begin{array}{l}\text { Internal Locus of Control } \\
\text { Index }\end{array}$ & & 200 & 0.33 & 1.00 & 0.6769 & 0.1490 \\
\hline Self-Efficacy Index & & 200 & 0.00 & 1.00 & 0.7806 & 0.1518 \\
\hline Agreeableness-Antagonism & & 200 & 0.36 & 1.00 & 0.8034 & 0.1467 \\
\hline $\begin{array}{l}\text { Conscientiousness-Lack of } \\
\text { direction }\end{array}$ & & 200 & 0.33 & 1.00 & 0.7868 & 0.1397 \\
\hline Extraversion-Introversion & & 200 & 0.00 & 1.00 & 0.5856 & 0.2014 \\
\hline $\begin{array}{l}\text { Openness-Closed to } \\
\text { experience }\end{array}$ & & 200 & 0.16 & 1.00 & 0.6569 & 0.1531 \\
\hline $\begin{array}{l}\text { Neuroticism-Emotional } \\
\text { stability }\end{array}$ & & 200 & 0.00 & 0.84 & 0.3750 & 0.1958 \\
\hline
\end{tabular}

